Francisco Emanuel Matos Brito Doutor em Ciências Sociais (UFBA). Pesquisador do Núcleo de Estudos Ambientais e Rurais/FFCH/UFBA.

E-mail:frabrito@ufba.br

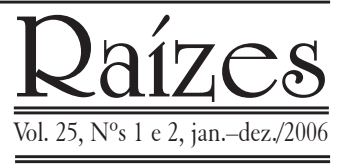

Trabalho recebido em:

$10 / 03 / 2006$

Aprovado para publicação em:

$23 / 03 / 2007$

\title{
AS CIÊNCIAS SOCIAIS FAZEM AS MALAS E CONTRIBUEM PARA O ESTUDO DAS VIAGENS E DO TURISMO
}

\section{RESUMO}

Este artigo analisa a viagem e o turismo, entendidos como empreendimentos nos quais as pessoas buscam distinção e status, engajam-se em atividades recreativas e até de aprendizado sobre a realidade dos locais visitados. Neste processo, utilizo o aporte teórico das ciências sociais, evidenciando a importância desta contribuição para a análise da atividade turística Abordo, também, a implementação desenfreada do turismo de massa induzida pelos empréstimos das instituições multilaterais e as críticas a este dirigidas pelos estudiosos e pelas populações dos destinos. Analiso o surgimento de algumas formas alternativas de turismo - enquanto resultantes deste processo - que, decorridos alguns anos de implementação, repetem muitos dos problemas causados pelo turismo de massa, tornando-se também alvo de muitas críticas.

Palavras-chave: ciências sociais, viagens distintivas, turismo de massa, formas alternativas de turismo, impactos do turismo

\section{SOCIAL SCIENCES PACK THEIR BAGS AND CONTRIBUTE IN STUDYING TRAVEL AND TOURISM}

\begin{abstract}
This article analyzes the travel and tourism, understood as undertaking, where people search distinction and status, get involved in leisure activities and learning activities about realities of visited places. In this process, I utilize the theoretical approach of social sciences, showing up the importance of this contribution to the touristic activity analysis. I also investigate the accelerated non-planning of mass tourism, which was induced by the loans made by various institutions and criticism to this process done by theorists and by local population. I analyze the appearance of some trades in alternative forms of tourism - as resulting from that process - which, after some years of its implementation, repeat many problems caused by the mass tourism, becoming objet of many criticisms.
\end{abstract}

Key words: social sciences, distinctive travels, mass tourism, alternative forms of tourism, tourism impacts 


\section{AS CIÊNCIAS SOCIAIS E A PASSAGEM DA VIAGEM PARA O TURISMO}

A primeira característica dos viajantes que foram além do simples turismo é não encontrar o que esperavam, ou o que buscavam [...], já que a maioria das pessoas vê apenas o que quer ver. A viagem torna-se uma arte quando as surpresas se transformam em vantagem. (Zeldin, 1996)

Quando se fala em viagem, vem à memória das pessoas uma série de significados expressando o deslocamento de um lugar para outro com os mais variados fins, seja de achar novas terras para exploração comercial das riquezas, para conhecer novas culturas e contato com a natureza como ingredientes importantes para aquisição de experiência de vida, seja com fins científicos, característicos das expedições às várias regiões do planeta e das pesquisas de campo dos cientistas sociais, viagem de catequese ao 'novo mundo' e visita aos templos religiosos, efetuadas pelos peregrinos e, também, para expressar sua transmutação no turismo com o deslocamento cada vez mais crescente de pessoas que buscam nos seus períodos de folga ou férias visitar aqueles locais ricos em atrativos naturais que lhes possibilitem encantamento, prazer e diversão, ironicamente chamados por Turner \& Ash (1991) de 'periferia do prazer'.

Vale salientar que além de um deslocamento no espaço a "viagem" inscreve-se simultaneamente no espaço, no tempo e na hierarquia social (Lévi - Strauss, 1996). Como exemplo de prática distintiva e conferidora de status, podese mencionar o Grand Tour, hábito cultivado pela aristocracia inglesa, entre os séculos XVI a XVIII, que consistia em estimular os filhos aristocratas a realizarem uma grande viagem, com duração de um a dois anos, ao continente europeu com o objetivo de complementação de estudos, adquirindo neste périplo o aprendizado, o bom gosto e a experiência de vida necessários àqueles que, mais tarde, viriam a fazer parte da classe dirigente inglesa e, também, considerados pessoas cultas, porque 'viajadas'.

Falando da importância marcante da viagem para a humanidade Ianni (2000) afirma que:

a história dos povos está atravessada pela viagem, como realidade ou metáfora. Todas as formas de sociedade [...] trabalham e retrabalham a viagem, seja como modo de descobrir o "outro", seja como modo de descobrir o "eu". É como se a viagem, o viajante e a sua narrativa revelassem todo o tempo [...] o conhecido e o desconhecido, o próximo e o remoto [...].
Ao lado da viagem de cunho espontâneo, observa-se a existência de sua contraface traduzida na viagem dos degredados e da mão de obra escrava no período colonial e, atualmente, os exemplos mais evidentes são os dos migrantes dos países do terceiro mundo - alvo da xenofobia européia e americana - os nômades, os exilados, os fugitivos, etc. Embora muito se fale na ocorrência de uma 'democratização' das viagens, este usufruto continua restrito para aqueles de maior poder aquisitivo. Reforçando esta constatação e traçando um paralelo entre os habitantes do Primeiro Mundo e do Segundo Mundo, Bauman (1999) afirma que:

os primeiros viajam à vontade, divertem-se bastante viajando [...], são adulados e seduzidos a viajar, sendo sempre recebidos com sorrisos e braços abertos. Os segundos viajam às escondidas, às vezes pagando por uma terceira classe superlotada num fedorento navio sem condições de navegar mais do que outros pagam pelos luxos dourados de uma classe executiva - e ainda por cima são olhados com desaprovação, quando não presos ao chegar.

Ainda de acordo com Bauman (1999) "a combinação da anulação dos vistos de entrada com o aumento dos controles de imigração [...] Revela a dimensão global de todo privilégio e de toda privação, por mais localizados”. Assim, para os primeiros, os vistos de entrada foram abolidos porque são bem-vindos, e para os segundos os controles de imigração tornaram-se ainda mais rigorosos, por serem considerados indesejáveis.

Vale dizer que o desempenho do ofício de Cientista Social encontra-se também associado ao ato de viajar, seja como realidade seja de maneira figurada. Ao se reportar à viagem como um recurso comparativo importante para o estudo das mais diversas configurações e movimentos da realidade, Ianni (2000) ressalta que "todo cientista social realiza algum tipo de viagem quando estuda, ensina ou pesquisa.[...] Por toda a história das Ciências Sociais, os principais autores têm sido viajantes ocasionais ou permanentes".

Ao enfocar este assunto, Clifford (1997) depois de identificar a existência de duas visões sobre a viagem: "negativamente vista como transição, superficialidade, turismo, exílio e desenraízamento [...] positivamente concebida como exploração, pesquisa, fuga, encontro transformador" (tradução nossa), concebe a viagem como "inclusiva abarcando uma variedade de praticas mais ou menos voluntaristas de sair de casa para um outro lugar [...] com o propósito de obter conhecimento e/ou ter uma "experiência"'supra, 
p.66). Ao viajar de casa para outro lugar (onde ocorrerá o trabalho de campo) o pesquisador vivencia situações liminares, conforme também demonstra Da Matta (1978) ao deslocar-se e afastar-se de sua sociedade e cultura. Clifford propõe que o fazer antropológico na forma de trabalho de campo seja encarado como o lócus de "encontros de viagem" (ibidem, p.67).

Nas Ciências Sociais pode-se mencionar a grande viagem realizada por Lévi-Strauss, registrada em Tristes Trópicos, pontilhada pelo encantamento com a paisagem, pela alegria e aborrecimento no percurso, pela busca e encontro com o outro ('o exótico’) e consigo ('o eu’), pela pesquisa e análise científica e pelas reminiscências e reflexão existencial. Lévi-Strauss inicia seus 'relatos de viagem' com a afirmação, "odeio as viagens e os exploradores. E eis que me preparo para contar minhas expedições” (1996, p.15), a qual tem sido utilizada à exaustão para demarcar campo entre as atividades desenvolvidas nas viagens pelos antropólogos e seus parentes indesejados, os turistas.

Entre demonstrações de desconforto presentes em muitas passagens do livro, Lévi-Strauss escreve suas impressões de antropólogo-viajante sobre os lugares, tendo uma delas ganho notoriedade ao ser comentada numa canção de Caetano ${ }^{1}$. A seguir, o autor demonstrando seu conhecimento sobre o potencial turístico de um local convida os visitantes a acampar, porém, no mesmo instante, arrepende-se, ao antever a ocorrência dos mais variados impactos ambientais a partir da chegada dos turistas:

Campistas, acampai no Paraná. Ou melhor, não: abstende-vos. Reservai aos últimos recantos da Europa vossos papéis engordurados, vossos frascos indestrutíveis e vossas latas de conserva abertas. Espalhai por ali a ferrugem de vossas barracas. Porém, mais adiante da franja pioneira e até a expiração do prazo tão curto que nos separa de sua pilhagem definitiva, respeitai as torrentes fustigadas pela espuma recente, que descem aos saltos dos degraus cavados nos flancos violeta dos basaltos. Não pisoteais os musgos vulcânicos de ácido frescor; [...]. (ibidem, p.143).

Esta citação encerra um paradoxo. Ao tempo em que recomenda que os turistas mantenham-se afastados, ele próprio ao descrever a beleza, a fragilidade, a riqueza da paisagem - 'com suas torrentes aos saltos' e 'seus musgos vulcânicos'- e ao prever a degradação anunciada da paisagem 'com a penetração de sua virgindade pela pilhagem definitiva' (a exemplo dos catálogos turísticos), nada mais faz do que açular o imaginário do turista transformando cada recomendação num convite, num apelo para que os turistas venham consumar tudo aquilo que o autor se esforça para evitar.

Conforme já mencionado, a viagem implica no deslocamento de idéias e de corpos transportados e em movimento. Neste processo o viajante "é um intermediário, coloca em comunicação lugares que se encontram separados pela distância e pelos hábitos culturais” (Ortiz, 1997) tornando-se, deste modo, o representante mais próximo do seu 'mundo' distante. Este viajante pode ser um estrangeiro que segundo Simmel (1983) desperta um duplo sentimento:

está próximo, na medida em que sentimos traços comuns de natureza social, nacional, ocupacional, ou genericamente humana entre ele e nós. Está distante, na medida em que estes traços comuns se estendem para além de nós, e nos ligam apenas porque ligam muitíssimas pessoas.

A tensão que se estabelece entre esta relação de proximidade e distância faz com que os contatos mantidos por este e pelo turista, com os moradores das localidades sejam, na maioria das vezes, marcados pela impessoalidade porque, de acordo com Simmel, ”os estrangeiros não são realmente concebidos como indivíduos, mas como estranhos de um tipo particular" (ibidem, p.187). Georg Simmel é o principal representante do formalismo sociológico e tem dado uma importante contribuição com suas idéias originais, sobretudo, através das noções de "estrangeiro" e "aventura" aplicadas ao estudo do turismo. Para Simmel, a viagem também comporta a aventura concebida por ele como um acontecimento que "extrapola o contexto da vida” (1998, p.171). Diferentemente do acaso e de outros atos que apenas roçam a epiderme da vida, quando a aventura ocorre é como se a vida existisse somente para proporcioná-la e traduzí-la num momento radical. Por compreender situações imprevistas - consideradas 'loucura', pelos mais velhos e 'excitante', pelos jovens - a jornada do aventureiro também envolve a possibilidade de riscos com os quais, segundo o autor, ele terá que se relacionar:

Na música $O$ Estrangeiro, o compositor depois de mencionar o encantamento dos olhares estrangeiros do pintor Paul Gauguin que "amou as luzes da Baía de Guanabara" e do cantor Cole Porter que "adorou as luzes na noite dela” canta que "o antropólogo Lévi-Strauss detestou a Baía de Guanabara, pareceu-lhe uma boca banguela”. 
O aventureiro [...], trata o que na vida é incalculável [...] a atividade do aventureiro freqüentemente parece loucura aos olhos do homem sóbrio, porque, para que tenha sentido, ela parece ter como pré-requisito que o insondável seja sabido" (ibidem, p.178).

Neste artigo abordamos as mudanças experimentadas pela viagem até o surgimento do turismo, uma atividade tributária das inovações tecnológicas, decorrentes da revolução industrial, aplicadas aos meios de comunicação e aos transportes ferroviários, marítimos, rodoviários e aéreos. Desde então, a viagem deixa de se constituir num empreendimento daqueles poucos aquinhoados do período do Grand Tour, para se tornar usufruto de muitas pessoas que adquirem um 'pacote' com pagamento à vista ou parcelado.

Além de enfocarmos a importância da viagem para o ofício dos cientistas sociais, demonstramos como o turismo é promovido, especialmente, a partir do segundo pósguerra, pelas instituições multilaterais para várias partes do mundo, os impactos ocasionados, as críticas recebidas, a reciclagem realizada pelos atores sociais ligados ao turismo, pela incorporação da questão ambiental, nos anos 80 , a segmentação desta atividade com a implementação das formas alternativas de turismo, a exemplo do turismo histórico, cultural e do ecoturismo e a contribuição das ciências sociais na análise deste processo.

\section{A CONTRIBUIÇÃO DAS CIÊNCIAS SOCIAIS AO ESTUDO DO TURISMO}

A forma como ocorria o desenvolvimento do turismo de massa, atingindo os mais longínquos destinos e financiado com recursos de muitas agências multilaterais, não passou despercebida ao olhar atento de muitos cientistas sociais $^{2}$, cujas preocupações acadêmicas, antes dirigidas para outros objetos de estudo, passaram, gradualmente de acordo com o aumento da importância deste e seus impactos socioeconômicos e ambientais - a contemplar e, posteriormente, contribuíram para conformar o campo de estudos do fenômeno turístico.

Segundo Cohen (1984), as primeiras abordagens sociológicas do turismo ocorreram na Alemanha com o artigo clássico de Leopold von Wiese, em 1930, seguido do tratamento sociológico mais completo dado ao assunto realizado por H. J. Knebel, em 1960. Embora o turismo viesse experimentando uma rápida expansão depois do período pós-guerra, excetuando-se, sobretudo, o estudo crítico de Boorstin, em 1964, esta atividade continuou recebendo pouca atenção como tema de investigação sociológica. Somente nos anos 70 é que o turismo deixa de ser encarado como um tema meramente exótico e marginal e passa a ser estudado como uma especialidade sociológica a partir, dentre outros, dos artigos de Cohen (1979, 1984, 1995, 1996), do trabalho original de Mac Cannell (1976), da publicação de uma série de tratados e revisões, a exemplo da crítica contundente de Turner \& Ash (1991) e das coletâneas coordenadas por Smith (1989) e Kadt (1979), do texto de Crick (1989) e pelo livro de Urry, publicado na segunda metade dos anos 90.

Em que pese a magnitude econômica, social, cultural e ambiental do turismo, a importância dada pelas ciências sociais a este fenômeno patrocinado pelos governos, regulada pelas agências internacionais e apoiado pelas empresas multinacionais ainda é pequena. Segundo Cohen (1984) este pequeno interesse:

pode refletir, em parte, a visão do senso comum sobre o turismo como uma atividade frívola, superficial indigna de uma investigação séria, isto certamente também explica o fato de o turismo não ter sido bem integrado na tendência dominante da sociologia. (tradução nossa).

Ademais, como afirma Urry (1996), “conferir um sentido teórico à diversão, ao prazer e ao entretenimento, revelou-se uma tarefa difícil para os cientistas sociais. Existe relativamente pouca fundamentação na sociologia do turismo". Além do comportamento reservado dos cientistas sociais, os pesquisadores utilizariam os aportes teóricos da sociologia geral no tratamento das questões relativas ao turismo, pois, segundo Cohen (1979):

o problema metodológico no campo do turismo é semelhante ao encontrado em outros campos da sociologia aplicada. Estritamente falando, não existe nenhuma sociologia do turismo como se fosse um campo separado da teoria sociológica, assim como não existe uma sociologia do desporto. Em vez disso, o que existe é uma aplicação das teorias sociológicas gerais ao campo especial do turismo. (tradução nossa).

2 Pode-se mencionar, dentre outros, os exemplos de Boissevain com sua pesquisa antropológica sobre Halffarug, um vilarejo em Malta, publicada em 1969; Kadt sobre Os Católicos Progressistas no Brasil, nos anos 60; Daniel Boorstin com trabalhos sobre semiologia e Urry, que até os anos 80 dedicava-se ao estudo da Anatomia das Sociedades Capitalistas. 
Advogando a necessidade de constituir o turismo como ciência e agrupando os vários atores envolvidos com a atividade turística, segundo as posições defendidas por cada um deles, o antropólogo Jafar Jafari (1994) concebeu 4 plataformas de pesquisa: de defesa, advertência, adaptação e baseada no conhecimento. A primeira delas, a plataforma de defesa, tem suas origens a partir do pós-guerra, período no qual o turismo foi visto como uma das alternativas de reconstrução das economias de vários países e de desenvolvimento para outros. É integrada pelo setor público e privado que fazem a apologia desta atividade apontando a importância econômica do turismo como gerador de benefícios

econômicos (ocupa muita mão de obra; beneficia outros setores; é uma alternativa econômica viável para muitos países; gera divisas), [...] nãoeconômicos (preserva o ambiente natural e o criado pela mão do homem; recria tradições do passado; promove ativamente a cultura; estimula o intercâmbio entre culturas diferentes e fomenta o benefício da paz mundial) (idem, p.11) (tradução nossa).

Apesar das virtudes do turismo apregoadas pelos integrantes desta plataforma, observam-se as críticas iniciais ao turismo nos anos 60, que ganharão corpo na década seguinte, passando, assim, a constituir a plataforma de advertência que recebe contribuições de cientistas sociais, de entidades públicas ligadas à defesa da cultura e do meio ambiente, de instituições religiosas e da própria imprensa. Seus integrantes afirmam que

o turismo gera principalmente empregos de temporada e que não requerem mão-de-obra qualificada, que só beneficia as empresas turísticas e as grandes corporações, que destroem a natureza e a paisagem, que reduz os povos e suas culturas ao nível de artigos de consumo, e ocasiona desajustes na estrutura da sociedade anfitriã (ibidem, p.12) (tradução nossa).

Beneficiando-se dos debates realizados entre as duas plataformas anteriores, em torno dos impactos acarretados pelo turismo, surge a plataforma de adaptação defendendo, em contraposição ao turismo de massa, a implementação de formas alternativas de turismo a exemplo do turismo sustentável, sensível, alternativo, responsável, de nível local e o ecoturismo. Entre os defensores desta plataforma encontram-se estudiosos do turismo e do ecoturismo, entidades conservacionistas, consultores, operadores turísticos, ambientalistas e grupos religiosos. Reconhecendo as dificuldades o autor argumenta que as estratégias da plataforma de adaptação não estão totalmente desenvolvidas para abarcar o volume massivo do turismo gerado em todo o mundo. Pode-se exercer certa influência sobre as formas de turismo e as maneiras de praticá-lo, porém não é possível reduzir seu volume (ibidem, p.15) (tradução nossa).

A plataforma baseada no conhecimento além de ser colocada como um passo à frente em relação às suas predecessoras, por objetivar o estudo amplo e sistemático do turismo

busca apoiar-se em fundamentos científicos e, ao mesmo tempo, manter laços com as outras plataformas [...] tentando dar ao turismo um tratamento holístico: não se consideram somente seus impactos ou formas, mas o turismo em sua totalidade. O objetivo principal é a formação de um corpo de conhecimento científico sobre o turismo (ibidem, p.16) (tradução nossa).

Segundo o autor, esta plataforma tem o apoio de membros da comunidade acadêmica, de instituições de pesquisa voltadas para o turismo, de órgãos responsáveis pelas publicações de estudos sobre o turismo, das universidades e dos responsáveis pela realização de eventos sobre o tema.

O desenvolvimento do turismo de massa constituiu-se tanto em objeto de discussão versando sobre seus impactos sócio-econômicos e ambientais, quanto de questionamentos sobre a autenticidade da experiência turística e, também, no tocante à relação estabelecida entre os visitantes e residentes, assim como sobre os reflexos desta atividade no modo de vida das localidades. Coube ao historiador Daniel Boorstin, a realização de um trabalho pioneiro, nos anos 60 , que ainda hoje mantêm sua atualidade, contribuindo significativamente para todos aqueles que se dedicam ao estudo do turismo. No livro The image: A guide to pseudo-events in America este autor, ao traçar um perfil da sociedade americana, cria o conceito de pseudo acontecimentos inaugurando uma discussão teórica sobre a noção de inautenticidade da experiência vivenciada pelo turista, cujos desdobramentos persistem até hoje. Ao argumentar que os turistas estão interessados, sobretudo, em pseudo acontecimentos, ele afirma que:

estas 'atrações' [turísticas] oferecem uma experiência indireta, inventada minuciosamente, um produto artificial para ser consumido nos próprios lugares onde a coisa autêntica está tão disponível quanto o ar. Elas são formas pelas quais o viajante permanece sem contato com pessoas do lugar no próprio ato de vê-las como ‘atração' turística. Elas mantêm os nativos em quarentena enquanto o turista no conforto do 
ar condicionado os vê através da janela de vidro de seu ônibus. (Boorstin,1987) (tradução nossa).

Para Boorstin, enquanto o viajante goza de certa independência em relação ao trade turístico - conjunto de empresas que integram o ramo de negócios em turismo chegando a evocar aquela idéia de viagem do período do Grand Tour, o mesmo não acontece com o turista que, confinado numa 'bolha ambiental' erigida pelos operadores turísticos, espera que estes tomem todas as medidas em seu nome e benefício. Tais medidas compreendem, dentre outras, a seleção dos locais e atrações a serem visitadas, o isolamento da população hóspede e do cotidiano do destino visitado. Ao promover a distinção entre o viajante e o turista, Boorstin (1987) argumenta que "o viajante era ativo e ia à procura das pessoas, de aventura e de experiência. O turista é passivo [...] e espera que as providências da viagem sejam tomadas por outros, objetivando o seu bem estar” (tradução nossa).

Ainda de acordo com Boorstin, as pessoas viajam para ver se as imagens que elas já conhecem por intermédio dos guias e anúncios estão realmente no destino visitado. Assim, o país estrangeiro torna-se a confirmação de um pseudo acontecimento, pois, segundo este autor, "muito do nosso interesse provém da curiosidade sobre se nossa impressão lembra as imagens encontradas nos jornais, nos filmes e na televisão. [...] Nós viajamos para examinar a realidade pela imagem" (idem, p.116). Antes mesmo de Boorstin, Ernst Bloch já havia feito consideração semelhante sobre desejos estabelecidos previamente pelo visitante ao afirmar que o charme da viagem "se funda sobre uma beleza três quartos subjetivas, [...] resultante principalmente do distanciamento estabelecido pelo espectador e reflete, em grande parte, a imagem desejo do objeto colocado num lugar inatingível" (1976, p.443) (tradução nossa).

Confirmando esta constatação, pode ser mencionada, como exemplo, a viagem antecipada de Goethe com toda a carga de subjetividade desde a juventude, impregnada de familiaridade com a Itália proporcionada pelos relatos paternos e pela visualização diária de vários monumentos de Roma na própria casa. Conforme relata o próprio Goethe,

o que sobretudo atraía os meus olhares no interior da casa era uma série de vistas de Roma com que meu pai havia decorado uma das antecâmaras. [...] Todos os dias eu podia contemplar [...] o Coliseu, a praça de São Pedro [...] e vários outros monumentos. Essas imagens gravaram-se profundamente na minha memória, e meu pai, [...] condescendia, por vezes, em nos descrever esses objetos. (1986, p. 22).
Na primeira metade da década de 70, Dean Mac Cannell, através de seu livro "The tourist: a new theory of the leisure class", foi o primeiro sociólogo a vincular o estudo do turismo à teoria sociológica, utilizando nas suas análises os trabalhos de Marx, Durkheim, Lévi-Strauss e Goffman, trazendo assim, uma contribuição expressiva centrada na noção de "autenticidade encenada”. Mac Cannell, referindo-se à imagem depreciativa do turista, afirma que “ o termo turista está sendo cada vez mais utilizado como um rótulo depreciativo para alguém que parece contente com suas experiências obviamente inautênticas" (1973, p. 94) (tradução nossa). Para demonstrar que os turistas não se contentam somente com experiências superficiais e inautênticas nos locais que eles visitam, Mac Cannell utiliza a distinção feita por Goffman entre regiões de fachada (front) e de fundo (back), ou colocando em termos de encenação teatral, o palco da frente e o do fundo. Segundo Goffman (1975):

tomando como ponto de referência uma determinada representação distinguimos três papéis decisivos com base na função: aqueles que representam; aqueles para quem se representa; e os estranhos, que nem participam do espetáculo nem observam. [...] Os três papéis decisivos mencionados poderiam ser caracterizados baseando-se nas regiões a que o executante tem acesso: os atores apresentam-se nas regiões de fachada e de fundo; a platéia, somente na região de fachada; e os estranhos estão excluídos de ambas.

De acordo com Mac Cannell, os espaços turísticos podem ser combinados num continuum de seis espaços de encenação, que começa na região de fachada e termina na região de fundo. Assim, confinado na região de fachada e movido pelo desejo de deslocar-se para regiões de fundo - ou colocando em termos filosóficos, buscando superar o aparente para chegar à realidade - na tentativa de vivenciar experiências autenticas, é sempre possível que o turista caia na armadilha e seja levado a pensar que teve acesso a uma região de fundo - lócus de autenticidade quando, na realidade, ele entrou numa região de fachada previamente preparada como autêntica para sua visita, vivenciando, mais uma vez, neste local, mais um espetáculo de 'autenticidade encenada'.

Diversamente de Boorstin, Mac Cannel não critica esta autenticidade encenada, na medida em que considera que a movimentação dos turistas nestes espaços de encenação contribui para o aumento da consciência turística e enseja a possibilidade destes terem contato com os nativos e vivenciarem a sua realidade. A procura por autenticidade 
também faz com que os turistas na condição de peregrinos modernos viajem para visitar as atrações turísticas e 'estando lá' demonstrem uma atitude ritual como se estivessem diante de um monumento sagrado. Alguns deles sentem-se tão intensamente tocados pela atração turística, que não podendo reverenciá-la a sós, tornam-se irritados com a presença de uma multidão de turistas em volta da mesma, como se estivessem profanando aquele lugar sagrado (Mac Cannell, 1976).

Na sua obra, Boorstin revela-se um nostálgico da viagem individualizada - rica culturalmente e tributária do Grand Tour - que, gradualmente, passou a ser acessível a um número, cada vez maior, de pessoas, os turistas - viajantes de massa, retratados criticamente por ele. O turista estudado por Mac Cannell, é aquele jovem viajante surgido no contexto do turismo de massa.

A maneira como o sistema turístico encontra-se estruturado, leva este a moldar e subordinar quase sempre as manifestações culturais e os artefatos das áreas visitadas às conveniências da demanda turística, na forma de prestação de serviços, fazendo, na maioria dos casos, com que elas, deslocando-se do seu contexto original, sejam transformadas em mercadorias e reduzidas a mero espetáculo para 'turista ver' e em 'arte de aeroporto', produzidas em série para consumo em larga escala.

Aliás, o espetáculo é uma das marcas constitutivas do turismo. O sociólogo Guy Debord caracterizou a sociedade ocidental contemporânea como a sociedade do espetáculo, evento este, segundo o autor, entendido como "uma relação entre pessoas mediadas por imagens” (1997, p.14). Tanto as manifestações culturais, como o artesanato e muitas atrações (re)inventadas, quando utilizadas para consumo turístico, passam a integrar o processo de espetacularização dos lugares nos quais os elementos de visualização turística, mesmo que não sejam, devem não só parecer reais como também autênticos. Este autor apresentando uma concepção critica, afirma que o turismo enquanto "subproduto da circulação de mercadorias [e] circulação humana considerada como consumo, resumese fundamentalmente no lazer de ir ver o que se tornou banal" (1997, p.112).

Vale dizer que a existência do turismo se funda num mercado cuja organização, desde Thomas Cook - pioneiro que converteu o turismo numa atividade organizada e também acessível a um número maior de pessoas - vem, cada vez mais, aprimorando-se, integrado por compradores e vendedores de mercadorias na forma de 'pacotes' que funcionam como o passaporte para a utilização de vários outros tipos de mercadorias, relacionadas, dentre outros, aos meios de transporte, hospedagem, entretenimento e souvenirs dos locais visitados.

A própria relação entre turistas e moradores, por vezes, é marcada pela mercantilização na qual são comercializados, dentre outros, os mais variados bens como a tradição na forma de espetáculo e o artesanato na forma de souvenirs. Os empreendedores das localidades turísticas visando, muitas vezes, colocar mais uma atração no calendário de eventos recriam - quando não inventam - algumas manifestações culturais que são vendidas e convencem a audiência turística da sua autenticidade, quando, em muitos casos, são meras "tradições inventadas" (Hobsbawn \& Ranger, 1984), exemplares de "pseudo-acontecimentos" (Boorstin, 1964).

A produção em série de produtos do artesanato local antes de uso interno e, muitas vezes, reforçador da identidade do próprio grupo social - para atender ao consumo turístico, além de ressignificá-los, em razão das influências recebidas e das adaptações promovidas para atender aos interesses da demanda do visitante, ao longo do processo produtivo, também faz com que estes passem a fazer parte, juntamente com a fotografia, do chamado "círculo hermenêutico envolvido em boa parte do turismo" (Urry, 1996), através do qual o turista reconstitui o seu percurso narrando para as outras pessoas as principais características dos lugares visitados, e apresentando como provas de 'ter estado lá, as fotografias tiradas e os produtos do artesanato adquiridos, estes reduzidos a meros souvenirs e, em muitos casos, destituídos das características culturais que os originaram.

Com respeito à fotografia, esta se constitui no principal meio de comprovação para o turista, como marcadores simbólicos do tempo ('esta foto é do ano que passeamos em Veneza') e, em algumas situações, também testemunho da invasão de privacidade causada pelo visitante. Sontag (1986) no seu excelente ensaio, afirma que "a fotografia desenvolve-se com o turismo... [e a] viagem torna-se uma estratégia para acumular fotografias”, uma prática inerente a 'todo turista que se preze'.

\section{ABORDAGENS SOBRE OS TURISTAS, O TURISMO E A OFERTA DE NOVOS PRODUTOS}

Baseado no fato de que a experiência turística combina graus de novidade com graus de familiaridade vivenciados cotidianamente pelo turista e, também, o excitamento 


\section{Francisco Emanuel Matos Brito}

da mudança com a segurança dos velhos hábitos, Cohen (1995) afirma a existência de um continuum de possíveis combinações entre novidade e familiaridade e classifica os turistas em quatro tipos: o turista de massa organizado, o turista individual de massa, o explorador e o mochileiro. Os dois primeiros representam os turistas institucionalizados, pela estreita relação mantida por estes com o sistema turístico, e os dois últimos os turistas não institucionalizados que, na melhor das hipóteses, mantêm ligações remotas com o sistema turístico.

Nesta classificação, em que fica evidenciada a influência da fenomenologia de Schutz através do emprego de categorias como a estranheza e a familiaridade para dar conta das motivações dos turistas, Cohen considera a experiência turística e a atitude destes nos locais visitados. Noutros trabalhos (1979, p.21-22 e 1996, p.93-104), Cohen identifica 5 modos de experiência turística. Em termos sumários, pode-se dizer que os dois primeiros buscam o prazer na diversão e na recreação (o diversional e o recreacional) e os 3 últimos, refletindo a influência recebida pelo autor da sociologia da religião, representam passos progressivos da identificação da experiência turística com a peregrinação (o experiencial, o experimental e o existencial).

Smith (1989), baseando-se nas atividades a que se dedicam os turistas nos locais visitados, define 5 tipos de turismo:1-turismo étnico, procura conhecer os costumes e as manifestações culturais; 2-o turismo cultural que visita as sociedades rurais para conhecer o modo de vida, culinária, festas; 3-turismo histórico que procura os museus, igrejas, ruínas e outros monumentos históricos da sociedade visitada; 4-turismo ecológico visita locais distantes, dotados de beleza natural através de uma viagem de cunho educacional e de contato com a cultura local; 5-turismo recreacional, igual ao descrito por Cohen é o típico turismo de massa em que se busca diversão e prazer nas praias, balneários etc. Derivada desta classificação, a autora (ibidem, p.11-14), tomando como referência a quantidade de visitantes e o grau de adaptação destes aos costumes locais, divide os turistas em 7 tipos: 1-o explorador; 2-de elite; 3-alheio aos circuitos; 4-não usual; 5-massa incipiente; 6-massa e 7-charter.

A colocação dos turistas na condição de peregrinos feita por Mac Cannell, tem levado alguns autores a enxergar nas situações vivenciadas pelos turistas, similaridade com os ritos de passagem ou de 'transição' estudados por Gennep (1960, p. 11) e divididos em três fases: separação, transição e agregação. Turner (1974) retomando as idéias analisadas por este autor, discute a situação de liminaridade (transição) do processo ritual no estudo das peregrinações religiosas. Urry (1996), efetuando uma síntese da análise de Turner sobre os peregrinos salienta que:

Importantes rites de passage estão presentes no movimento de um estágio para outro. Esses estágios são três: o primeiro deles é a separação social e espacial do lugar normal de residência e dos laços sociais convencionais; o segundo é a liminaridade, em que o individuo encontra-se em uma 'antiestrutura... fora do lugar e do tempo' - os laços convencionais são suspensos, é vivenciada uma 'comunitas', na qual as ligações são intensas e ocorre uma experiência direta do sagrado e do sobrenatural; o terceiro é a reintegração, em que o individuo é reintegrado ao grupo social anterior, habitualmente a um status social mais elevado.

Realizando uma analogia e transpondo esta análise para o comportamento do turista, pode-se dizer que o turismo, em termos de situações liminares, possibilita que o turista entre de férias do trabalho, da vida cotidiana e chegue aos destinos visitados a também entrar, por vezes, de férias dos valores, passando a ter comportamentos inusitados que ele não tem no seu local de origem e a vivenciar experiências que propõem a inversão de papéis do tipo 'rei / rainha por um dia' etc. Depois de se deslocar de casa para um lugar distante, o turista retorna ao ponto de partida podendo ter vivenciado tanto uma experiência enriquecedora e relaxante quanto uma - indesejada e, cada vez mais, possível - experiência que reproduza a sua rotina de trabalho.

A proliferação do turismo de massa, inicialmente dirigida para os países situados no mediterrâneo, passa, posteriormente, a ser estimulada pelo sistema turístico para os vários rincões do planeta, incluídos aí os países do $3^{\circ}$ mundo, ocasionando, decorridos alguns anos, toda a sorte de problemas sociais, ambientais e culturais, que provocaram a reação dos movimentos sociais, contribuindo, assim, para a colocação de um freio na velocidade com que o ufanismo vinha sendo disseminado, fazendo emergir uma dose de prudência necessária nos governos e promotores da atividade. Dentro deste espírito instaurador de questionamento, pode-se mencionar a coletânea de artigos “Tourisme. Passeport pour le développement?", coordenada pelo sociólogo Emanuel de Kadt e publicada conjuntamente pelo Banco Mundial e pela UNESCO. Diante da evidência dos efeitos sociais e culturais perversos, provocados pelo turismo, e da necessidade de abordá-los de maneira mais sistemática, estas duas instituições promo- 
veram, em dezembro de 1976, um ciclo de estudos com a participação de representantes de 18 países, dentre os quais, 11 países em desenvolvimento, da África, Ásia e América Latina, incluindo o Brasil.

As medidas recomendadas (Kadt, 1979), resumidamente, dizem respeito a: 1) distribuição dos projetos de acordo com os tipos de turismo que estes países têm condições de desenvolver; o planejamento dos países receptores deveria ser interdisciplinar, tentando integrar o turismo aos outros setores; buscar a preservação e o desenvolvimento do patrimônio cultural e nacional e estar atento para os problemas sociais, econômicos e ambientais; estímulo à participação dos atores sociais locais nos projetos turísti$\cos ; 2$ ) os aspectos culturais do turismo e a relação estabelecida entre turistas e população receptora e o tipo de infra-estrutura disponível; 3) incentivo à cultura local como forma de beneficiar os habitantes e os turistas (tradução nossa).

A este evento sucederam-se manifestações que também buscavam colocar uma certa ordem na forma desenfreada como o turismo de massa vinha sendo implementado, a exemplo das críticas formalizadas por entidades representativas das populações hóspedes (Lea, 1993), organizações religiosas como a Coalizão Ecumênica sobre o turismo no $3^{\circ}$ mundo que além de combater a presença de drogas, prostituição e exploração racial presente nesta atividade, elaborou um código de ética - no qual indica o comportamento mais adequado a ser adotado pelos turistas - e vem promovendo encontros de igrejas preocupadas com os estragos causados pelo turismo nos países receptores (Crick, 1989; Lea, 1993).

A Igreja Católica representa um capítulo à parte na sua relação com a atividade turística. O Arcebispo de Cantuária, apud Urry (1996) afirma que "na Idade Média as pessoas eram turistas devido a sua religião, ao passo que hoje elas são turistas porque o turismo é sua religião". Quando fala dos tempos atuais dizendo que 'o turismo se transformou na religião dos viajantes’ ele evoca tanto a idéia defendida por Mac Cannell (1976) de que o turista de hoje seria um peregrino que, ao invés das imagens sagradas, teria como objeto de adoração as principais atrações turísticas distribuídas pelas várias cidades do mundo, quanto a concepção de Cohen $(1979,1996)$ sobre os modos de experiência turística baseados na idéia de peregrinação e de Graburn (1989) que concebe o turismo como uma viagem sagrada.

Concordamos em parte com Burke (1996) quando afirma que, "num certo sentido, os turistas são uma versão secularizada dos peregrinos medievais, suportando o desconforto a fim de adquirir um mérito cultural e social, e não mais religioso", embora nem todos se mostrem dispostos a enfrentar situações de desconforto e, tampouco, estão interessados em adquirir mérito de qualquer natureza, uma vez que objetivam, tão somente, a recreação e a diversão.

Desde 1969, através do documento Peregrinans in terra, a Igreja vem acompanhando o desenrolar do turismo. Decorridos mais de 30 anos, esta instituição publicou um documento intitulado Orientações para a Pastoral do Turismo, cujo objetivo é "colaborar para que tanto paróquias como dioceses tenham sensibilidade e, mais que isto, subsídios para elaborarem em nível local, os seus planos de pastoral envolvendo a questão do turismo" (SEDOC, 2001). Ciente dos problemas ocasionados pelo turismo, a Igreja afirma que aquelas pessoas que promovem ou desfrutam desta atividade, "com freqüência, utilizam-na como meio para seus propósitos ilícitos, como instrumento de injusta exploração, como ocasião para a agressão às pessoas, às culturas ou à natureza" (idem, 282-283).

Apesar das críticas e recomendações, a Igreja - que tem no cristianismo um dos principais fornecedores do turismo (Barthes, 1978) - mantém uma relação estreita com o sistema turístico notadamente vinculado às peregrinações do turismo religioso de âmbito mundial e aos benefícios auferidos com vistas à conservação dos seus templos. Talvez isto explique o fato de a Igreja Católica - a exemplo das demais instituições religiosas - não chegar a condenar o turismo, acreditando, inclusive que, superados alguns problemas, a viagem poderia se constituir numa experiência enriquecedora.

Ainda fazendo parte do contexto marcado pela preocupação ambiental e pela crítica ao turismo de massa, realiza-se, em agosto de 1989, na Polônia, a Conferencia de Zakapone, promovida pela Academia Internacional para o Estudo do Turismo. Os participantes deste evento, após analisar criticamente o termo turismo alternativo, consideraram-no tanto uma ideologia, que surgiu como reação às conseqüências indesejáveis do turismo ocidental, quanto um conceito cheio de ambigüidade e, após várias discussões, chegaram à conclusão de que:

o termo tinha pouco valor como conceito científico e considerando-se a variedade das formas de turismo - cada qual com potencial para gerar conseqüências desejáveis e indesejáveis - acharam por bem substituir o termo pela expressão formas alternativas de turismo (Nash,1992, e Smith \& Eadington, 1992) tradução nossa. 


\section{Francisco Emanuel Matos Brito}

Estas formas alternativas de turismo - já abordadas por Cohen e Smith - significam, em princípio, uma reação ao turismo de massa e, em certa medida, recolocam a necessidade de um turismo em menor escala, contraposto ao gigantismo dos empreendimentos massificados, a preocupação com a natureza e com a situação das populações locais.

Com respeito à reação dos turistas, esta atinge o seu ápice por volta dos anos 90. Cansados de terem seus olhares dirigidos para as atrações selecionadas nos guias ${ }^{3}$ e catálogos das agências de turismo, saturados de multidões e conscientes das mazelas sociais e da degradação ambiental reforçadas nos vários destinos, boa parte destes turistas passou a buscar formas de turismo diferentes daquela praticada até então.

A 'indústria turística', até o momento resistente, diante das pressões e críticas verificadas em escala internacional, aproveita o apelo social e ambiental para realizar a reciclagem interna que vai desde a tomada de medidas, visando adaptar seus empreendimentos de forma a reduzir os impactos sociais, culturais e ambientais, até a segmentação do mercado com a oferta de novos produtos turísticos para um tipo de consumidor, que, tendo se tornado exigente, reage ao empacotamento e à padronização (Urry, 1996) passando a demandar produtos mais especializados e exclusivos (Krippendorf, 1989) que, absorvidos pelo mercado, no decorrer de alguns anos de implementação, ocasionam problemas socioeconômicos e ambientais nos vários destinos, transformando-se, em muitas oportunidades, na versão 'alternativa' do turismo de massa e, por isso, tornando-se alvo de muitas críticas da parte dos estudiosos e dos moradores das localidades atingidas.

Bourdieu (1979), fala da nova pequena burguesia como aquela fração de classe que está "distribuída nas profissõos de apresentação e representação e em todas as instituições dedicadas à venda de bens e serviços simbólicos”. Assim, esta fração de classe considerada os intermediários culturais "se sentem como "inclassificáveis", "excluídas", "marginais”, em vez de ser classificadas, ligadas a uma classe, a um lugar determinado no espaço social” (supra, p. 429). Em que pese a recusa à colocação numa classe, ela acaba sendo naturalmente classificada pelos seus próprios gostos e práticas ${ }^{4}$ culturais, educativas, sexuais e de lazer que vão da 'agricultura biológica a zen'. Tais práticas já inscritas na contemporaneidade e denominadas alternativas, acabam classificando esta fração da classe média e pondo-a 'no seu devido lugar'.

A imitação e a popularização de tais práticas, características do estilo de vida intelectual, tomadas de empréstimo e transmitidas por esta fração da classe média para uma grande audiência, significa uma das "tantas maneiras que tem o pequeno para fazer de grande" (Bourdieu, 1994), buscando compensar a baixa proporção de capital econômico com o aumento do montante de capital cultural. Neste processo, a pequena burguesia, além de consumidora, também atua como "autênticos empresários culturais, visando legitimar a intelectualização de novas áreas do saber especializado, como música popular, moda, design, férias, esporte, cultura popular" (Featherstone, 1995), podendo-se acrescentar o turismo.

Munt (1994) também se refere à intelectualização e acrescenta a profissionalização da viagem e a utilização de um discurso e uma prática como as formas pelas quais a pequena burguesia busca estabelecer a distinção no turismo. A profissionalização atinge não só a viagem como também aqueles que se encontram na direção de operadoras, agencias e ONGs, cuja experiência e competência são exaltadas e utilizadas como um trunfo a mais para vencer a concorrência, bem como maximizar a distinção entre turistas e viajantes, presente nos anúncios das operadoras que criticam os roteiros convencionais do turista de massa e ressaltam os predicados dos viajantes e das viagens, qualificadas como seletivas.

A estes três elementos, associam-se as lutas espaciais hegemônicas, "utilizadas pelas novas classes médias que precisam adotar estratégias de exclusão para procurar proteger as novas mercadorias da viagem" (idem 1994, p.117) (tradução nossa) ou novos destinos turísticos, vendidos

\footnotetext{
3 Barthes (1978) referindo-se ao Guide bleu, mas que pode ser generalizado para os demais guias turísticos, afirma que o "guia transforma-se no oposto daquilo que se proclama: num instrumento de cegueira" por restringir a vida do lugar à seleção de uns poucos monumentos para visitação e a alguns aspectos pitorescos.

4 Vale citar algumas práticas relacionadas por Bourdieu (1979) como características do estilo de vida da nova pequena burguesia: "agricultura biológica, anti-nuclear, anti-psiquiatria, astrologia, bio-energia, corpos, dietético, droga, ecologia, esoterismo, extraterrestre, folclore, futurologia, Gestalt - terapia, homeopatia, homossexualidade, medicina oriental, meditação transcendental, macrobiótica, nômades, nãoviolência, parapsicologia, tecelagem, vegetarianismo, vida comunitária, vôo livre, viagem, yoga, zen”. (tradução nossa).
} 
pelas operadoras como áreas 'livres de turistas', 'distante das veredas batidas pelo turismo'.

Abordando como as empresas turísticas utilizam a questão ambiental, procurando conseguir legitimação espacial, Munt (1994) afirma que, graças à utilização de tais expedientes, e ao emprego do conceito de sustentabilidade e respeito à capacidade de carga, como justificativas para se estabelecer a exclusividade sobre o natural, determinadas áreas "são freqüentemente reservadas para consumo dos perspicazes ecoturistas ocidentais" (idem, 1994, p.119). O apelo ambiental e a sensibilidade cultural têm se constituído em símbolos de estilos de vida e elementos de atração das classes médias ecoturísticas e afins, que desejosas de distinção espacial das multidões de turistas, deslocam-se para o terceiro mundo esperando vivenciar experiências autênticas nestas áreas reservadas.

Urry é outro autor que aborda a disseminação de um estilo classe média no turismo, enfocando como a percepção que esta passa a ter do natural influi na afirmação de um tipo de viagem anunciada pelos guias impressos e dirigidas ao viajante independente em contraposição ao turista convencional (de massa). Assim, as férias verdadeiras deveriam ter duas características principais:

visitar um lugar bem distante daqueles que o grosso da população estará visitando. Os exemplos incluem as ilhas Maldivas, a Síria ou a Bolívia. [...]. Em segundo lugar, o turista autêntico recorrerá a pequenas agências e operadores para ir até os lugares escolhidos. O guia refere-se ao desenvolvimento do agente de viagens "delicatessen", isto é, aquelas agências especializadas que designam certos operadores para uma clientela independente, exigente (Urry ,1996).

Esta tendência anunciada na segunda metade dos anos 80 ganha impulso nos anos 90 e é reafirmada na década seguinte pela Organização Mundial do Turismo - OMT. Esta entidade também estima para os próximos 20 anos (2000 - 2020) que "as férias com a prática de mergulho e esportes, o turismo cultural, rural e as viagens baseadas na natureza em partes primitivas da Ásia e da África, estarão entre as áreas de maior crescimento nas próximas duas décadas" (Foroohar, 2002) tradução nossa.

\section{AS CIÊNCIAS SOCIAIS E O ESTUDO DO TURISMO NO BRASIL}

A reflexão de maneira mais sistemática sobre o fenômeno turístico no Brasil ganha corpo na década de 90, referenciada na luta do movimento ambientalista iniciada na Europa que reverbera o conceito de desenvolvimento sustentável, cuja visibilidade adquirida na Conferência de Estocolmo, consolida-se na Eco 92, passando a fazer parte dos discursos dos vários atores sociais envolvidos com a questão ambiental e com os rumos do desenvolvimento. Some-se a isto, a implementação de projetos e pesquisas realizadas nas áreas litorâneas que acabavam registrando direta ou indiretamente os impactos do turismo sobre a população destas localidades.

Do mesmo modo, podem ser mencionadas as políticas públicas ligadas, tanto à proteção e ao ordenamento ambiental em áreas litorâneas e interioranas, quanto àquelas voltadas diretamente para o desenvolvimento do turismo, aliadas à proliferação de cursos de turismo e hotelaria, verificada neste período, e à realização de eventos nacionais - a exemplo do Encontro Nacional de Turismo com Base Local, prestes a chegar à décima edição este ano - que, conjuntamente, têm tido grande importância, não só relativa ao incremento do número de estudos, como também, no que diz respeito ao amadurecimento gradual e à incorporação de novos temas ao debate sobre esta atividade.

Em termos sucintos, pode-se afirmar que esta produção científica no âmbito das Ciências Sociais, cuja atitude manifestada pelos pesquisadores na análise do turismo, também pode ser distribuída nas quatro plataformas criadas por Jafari (1994), vem se dedicando á discussão de vários temas que, inclusive, têm integrado a publicação de coletâneas, a exemplo do estudo dos impactos socioambientais do turismo (Lemos, 1996); das mudanças experimentadas pela viagem, do processo de urbanização e da sustentabilidade turística (Serrano et al., 2000); da busca da autenticidade na experiência turística e da relação entre turismo, cultura, identidade e globalização (Banducci Jr. \& Barretto, 2001).

Vale salientar que, ao longo deste processo, o turismo foi se constituindo em objeto de reflexão por parte de vários cientistas sociais, à medida que este fenômeno crescia de importância e conforme a magnitude dos impactos ocasionados por esta atividade nos vários destinos nacionais. Atualmente, o campo de estudos sobre o turismo baseia-se num conhecimento que, além de estar sendo produzido e demandando uma reflexão sistemática, encontra-se marcado pela multidisciplinaridade, traduzida na recepção de contribuições significativas e originárias, dentre outras, da sociologia, da antropologia, da economia e da psicologia. 


\section{CONSIDERAÇÕES FINAIS}

A variedade do cardápio oferecido, visando atender os gostos mais diferenciados, encontra-se também vinculada a uma expectativa de aumento, tanto do número de turistas, quanto da receita proveniente desta atividade. Para as 692,9 milhões de chegadas internacionais ocorridas em 2001, a OMT espera que este número ultrapasse a casa de 1 bilhão em 2010 e supere a marca de 1 bilhão e 550 milhões de turistas, em 2020.

Esta explosão projetada encontra-se na dependência da confirmação, tanto das tendências de longo prazo, algumas das quais em andamento - aumento da riqueza global, melhoria na tecnologia dos transportes, liberalização do espaço aéreo internacional, vôos mais baratos e o uso da Internet como uma ferramenta de viagem -, quanto da necessidade continuada de um número cada vez maior de pessoas que buscam escapar, por um tempo, das situações cotidianas enfrentadas nos centros urbanos. Entretanto, não se pode deixar de registrar que esta expectativa também é influenciada pelas demandas criadas regularmente pelas agências internacionais, tais como a OMT, o Banco Mundial e o BID, juntamente com os governos nacionais.Vale dizer que esta previsão considera apenas um cenário francamente favorável, não atentando para as crises do capitalismo, para os problemas enfrentados pela aviação civil, para os desastres ambientais e, muito menos, para os problemas políticos traduzidos nos vários atentados que vêm atingindo o próprio setor turístico.

A preocupação crescente com o turismo está diretamente relacionada ao crescimento e à continuidade da procura dos governos de países do terceiro mundo que seguem encarando esta atividade como alternativa de desenvolvimento e solução para os seus problemas econômicos. Sabedora e estimuladora destas expectativas, a OMT não só tem catalisado tal interesse, como também tem dado mostras de otimismo. Segundo as palavras de Francesco Frangialli, Secretário Geral desta instituição: "todos os países querem turistas. As pessoas [...] gostam de descobrir o mundo, elas estão cansadas do turismo de massa. Embora muitos países não tenham praias, eles podem oferecer montanhas, desertos e culturas únicas”. (apud Piore, 2002) tradução nossa.

À primeira vista causa estranheza que este discurso condenatório ao turismo de massa, ainda o principal vagão da locomotiva turística, venha de um dos representantes do patronato desta atividade. Na verdade, a OMT está ciente de que o turismo convencional continuará sendo, por muito tempo, a principal fatia e o segmento que responderá pelas maiores receitas do turismo. $\mathrm{O}$ estímulo e venda de outros 'produtos turísticos' - enquanto nichos de mercado desta atividade - como a 'solução lógica' para aqueles países que não detenham atrativos característicos do turismo de massa (praias), inscreve-se na estratégia do empresariado turístico internacional que não só diversifica economicamente a atividade, como também estende o seu alcance para as áreas mais longínquas e frágeis do planeta.

Nestas áreas, a chegada de turistas mais exigentes e com maior nível de conhecimento, tem colocado para os agentes turísticos a necessidade de um processo regular de capacitação para atender as demandas de intelectualização e profissionalização (Munt, 1994), postas por estes turistas, que informados por guias impressos como o Lonely Planet, desejam realizar uma viagem distintiva, encarada como uma oportunidade para aumentar o capital cultural (Bourdieu, 1979), requerendo das agências a contratação de especialistas ou a presença de guias com um conhecimento mais aprofundado sobre a flora, fauna, geologia e a história dos locais visitados, evocando, deste modo, as viagens de ilustração do período do Grand Tour.

Este comportamento turístico vem sendo exercitado nos vários destinos turísticos mundiais, sobretudo, a partir dos anos 80. Vale salientar que as áreas turísticas encontramse expostas a fatores conjunturais de ordem econômica e política, à concorrência entre destinos mundiais que oferecem produtos semelhantes, aos modismos que influenciam, sobremaneira, o gosto volúvel dos turistas, ao nível dos serviços prestados, à desigualdade social e, eventualmente, à violência, que podem, individualmente ou associados, comprometer profundamente a situação, não só de um destino, como também das condições de vida de seus moradores que, diante da restrição de alternativas econômicas, encontram-se maciçamente empregados no turismo. Assim, cabe a todos os agentes institucionais públicos e privados, responsáveis e envolvidos com o turismo em cada destino, a tarefa de implementar medidas de cunho sócio-econômico e ambiental que garantam a manutenção desta atividade sempre numa posição de destaque, como uma das estratégias para evitar que tais áreas se tornem vulneráveis a ponto de comprometer seu ciclo de vida como destinação turística e venham a se transformar em mais um destino intensamente explorado e abandonado pelos turistas que, seguindo o modismo da estação, partirão em busca de novidade em outros points. 
Diante do exposto, reafirmo, não somente a importância e sócio-econômica do turismo, como também a sua relevância como tema de estudo acadêmico por parte das ciências sociais. A estas, cabe uma tarefa importante relacionada, dentre outras, à investigação e abordagem sobre a relação estabelecida entre turistas e moradores, às implicações sociais, econômicas e ambientais provocadas pelo turismo nos destinos onde esta atividade se desenvolve e, também, à realização de novas pesquisas que busquem dar conta tanto das transformações, quanto dos processos que se verificam nas destinações turísticas nacionais e internacionais num contexto de mundo globalizado em que, cada vez mais, a humanidade encontra-se em movimento, embora admita, em sua maioria, que, apesar da volúpia de estar em trânsito, não há lugar melhor que o lar.

\section{REFERÊNCIAS BIBLIOGRÁFICAS}

BANDUCCI JR., A.; BARRETTO, M. Turismo e identidade local. Uma visão antropológica. Campinas: Papirus, 2001.

BARTHES, R. Mitologias. Rio de Janeiro - São Paulo: Difel, 1978. 74p.

BAUMAN, Z. Globalização: as conseqüências humanas. Rio de Janeiro: Jorge Zahar Editor, 1999.

BENJAMIN. W. A Obra de Arte na época de suas Técnicas de Reprodução. In:

Paulo: Abril Cultural, 1983, p.3-28.

BLOCH, E. Le Principe Espérance. Tomo I. Paris: Éditions Gallimard, 1976.

BOORSTIN, D. The Image: A guide to Pseudo - Events in America. New York: Atheneum, 1987. 85p.

BOURDIEU, P. La distinction - critique sociale du judgement. Paris: Les Editions de Minuit, 1979. p.333-340.

Gostos de classe e estilos de vida. In: ORTIZ,

R. (org.). Coleção Grandes Cientistas Sociais. São Paulo: Ática, 1994, p.82-121.

BURKE, P. Uma multidão de curiosos. Folha de São Paulo. São Paulo, 1996. p.9. Caderno Mais.
CLIFFORD, J. Routes: Travel and translation in the late twentieth century. Cambridge - London: Harvard University Press, 1997. 31p.

COHEN, E. Rethinking the sociology of tourism. Annals of Tourism Research. 1979, p.18-35.

. The Sociology of Tourism: approaches, issues, and findings. Annual review of Sociology, v.10, p.373392, 1984.

. Toward a sociology of international tourism. In: McINTOSH, R. W., GOELDNER, C. R., RITCHIE, R. B. (ed.). Tourism: principles, practices, philosophies. New York: John Wiley \& Sons, 1995, p.241-250.

Phenomenology of tourist experiences. In:

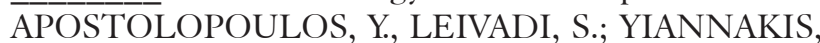
A. (ed.). The Sociology of Tourism. Theoretical and Empirical Investigations.London: Routeledge, 1996, p.90-111.

CRICK, M. Representations of international tourism in the social sciences: Sun, sex, sights, savings, and servility. Annual review of Anthropology, v.18, p.307-344, 1989.

Da MATTA, R. O ofício do Etnólogo ou como ter 'Anthropological Blues'. In: NUNES, E. (org.). A Aventura Sociológica. Rio de Janeiro: Zahar Editores, 1978, p.23 -35.

DEBORD, G. A Sociedade do Espetáculo. Rio de Janeiro: Contraponto, 1997.

ECUMENICAL COALITION ON THIRD WORLD TOURISM. Tourism Ethics. Code of Ethic for Tourists. http://www.ecotourism.org/ecumenfr.html>. 05 Ago. 2002.

FEATHERSTONE, M. Cultura de consumo e pós-modernismo. São Paulo: Studio Nobel, 1995. p.129.

FOROOHAR, R. Travel; Tourism: Getting Off the Beaten Track. Newsweek. New York, July 22-29, 2002, p.34-38.

GENNEP, A. van. The Rites of Passage. London: Routledge and Kegan Paul, 1960.

GOETHE, J. W. von. Memórias: poesia e verdade. Brasília: Universidade de Brasília, 1986. 
GOFFMAN, E. A representação do eu na vida cotidiana. Petrópolis:Vozes, 1 975. 135p.

GRABURN, N. Tourism: The Sacred Journey. In: SMITH, V. L. (org.). Hosts and Guests. The Anthropology of Tourism. 2.ed. Filadélfia: University of Pennsylvania Press, 1989, p.21-36.

HOBSBAWN, E.; RANGER, T. A invenção das tradições. Rio de Janeiro: Paz e Terra, 1984.

IANNI, O. A Metáfora da Viagem. In: Enigmas da modernidade - Mundo. Rio de Janeiro: Civilização Brasileira, 2000, p.11-31.

JAFARI, J. La cientifización del turismo. Estudios y Perspectivas en Turismo. Buenos Aires: CIET, v.3, n.1, p.7-36, 1994.

KADT, E. de. Tourisme, passeport pour le développement? Paris: Banque Mondiale/Unesco/Ed.Economica, 1979. p. $333-340$

KRIPPENDORF, J. Sociologia do Turismo - Para uma compreensão do lazer e das viagens. Rio de Janeiro: Civilização Brasileira, 1989.

LEA, J. Tourism development ethics in the Third World. Annals of Tourism Research, v.20, p.701-715, 1993.

LÉVI-STRAUSS, C. Tristes Trópicos. São Paulo: Companhia das Letras, 1996. 81p.

Mac CANNELL, D. The tourist: a new theory of the leisure class. New York: Schocken books, 1976.

MUNT, I. The 'Other' postmodern Tourism: Culture, Travel and the New Middle Classes. Theory, Culture, Society, v.11, p.101-123. 1994.

NASH, D. Epilogue: A research Agenda on the Variability of Tourism. In: SMITH, V. L.; EADINGTON, W. R. (orgs.). Tourism alternatives: Potentials and problems in the development of tourism. Filadelfia: University of Pensylvannia Press, 1992, p.216 - 225.

ORTIZ, R. A Viagem, o Popular e o Outro. In:

Um outro território. Ensaios sobre a mundialização. São
Paulo: Olho d'Água, 1997, p.29-47.

PIORE, A. Trouble in Paradise. Newsweek. New York, 2002, p.42-44.

SEDOC. Orientações para a Pastoral do Turismo. Petrópolis:Vozes, v.34, n.289, p.270-316, 2001;

SERRANO, C. M. de T., BRUHNS, H. T.; LUCHIARI, M. T. D. P. (orgs.). Olhares contemporâneos sobre o turismo. Campinas: Papirus, 2000.

SIMMEL, G. O Estrangeiro. In: FILHO, E. M. (Org.). Sociologia. São Paulo: Ática, 1983, p. 182-188.

A aventura. In: SOUZA, J.; OELZE, B. (orgs.). Simmel e a modernidade. Brasília: UNB, 1998, p.171-187.

SMITH, V. L. Introduction. In: SMITH, V. L. (org.). Hosts and Guests. The anthropology of Tourism. 2.ed. Filadélfia: University of Pennsylvania Press, 1989, p.11-17.

.; EADINGTON, W. R. Preface. In: SMITH, V. L; EADINGTON, W. R. (orgs.). Tourism alternatives: Potentials and problems in the development of tourism. Filadelfia: University of Pensylvannia Press, 1992, p.xiii $-x v$.

SONTAG, S. Ensaios Sobre a Fotografia. Lisboa: Dom Quixote, 1986. p18-19.

TURNER, L.; ASH, J. La horda dorada. Madrid: Endymion, 1991.

TURNER, Victor. O Processo Ritual. Petrópolis, RJ: Vozes, 1974. p.117-175

URRY, J. O olhar do turista: viagens e lazer na sociedade contemporânea. São Paulo: Studio Nobel/Sesc, 1996. 187p.

ZELDIN, T. Como os viajantes formam a maior nação do mundo, e como aprendem a não ver apenas aquilo que procuram. In: - Uma história íntima da humanidade. Rio de Janeiro: Record, 1996, p.268-280. 